\title{
The Relationship between Stress and Health-related Quality of Life is Mediated by Shoulder Pain, Shoulder Disorder, and Depression
}

Myung Kyung Lee

Kyungpook National University

Jihyun Oh ( $\sim$ grape0123@hanmail.net )

Daejeon University

\section{Research Article}

Keywords: mediators, mediation model, stress, quality of life, women

Posted Date: November 1st, 2021

DOI: https://doi.org/10.21203/rs.3.rs-1020292/v1

License: (c) (i) This work is licensed under a Creative Commons Attribution 4.0 International License.

Read Full License 


\section{Abstract}

The purpose of this study is to analyze the mediating effect of shoulder pain, shoulder disorder, and depression in the relationship between stress and health-related quality of life in middle-aged women using a serial mediation model. For this study, data was collected from middle-aged women aged between 35 and 64 living in Seoul, South Korea, from May 13, 2021 to May 23, 2021. Data regarding stress, health-related quality of life, shoulder pain, shoulder disorder, and depression were collected using a self-reported, structured survey. SPSS macro process (Model 6) was used, and the relationship between stress and health-related quality of life of participants were analyzed using serial mediation analysis using shoulder pain, shoulder disorder, and depression as variables. From the results of the study, it was observed that stress has a statistically direct impact on health-related quality of life. On performing serial mediation analysis, shoulder pain, shoulder disorder, and depression were found to be statistically significant, which predicts the relationship between stress and health-related quality of life; the variables showed an explanatory power of 33\% for influencing the quality of life. Therefore, the relationship between stress and health-related quality of life was found to be partially mediated by shoulder pain, shoulder disorder, and depression. This study suggests the need for healthcare workers to develop a method, such as exercise intervention programs based on various degrees and types of physical activity, for improving the health-related quality of life and reducing stress caused by shoulder pain, shoulder disorder, and depression in middle-aged women.

\section{Background}

Shoulder pain is the third most common musculoskeletal disease occurring in adults in general, with a fairly high lifetime incidence of $\geq 60 \%$ in adults $[1,2]$. In addition, in case of shoulder pain, it was found that the symptoms persist for $\geq 12$ months after the first onset in $\geq 60 \%$ participants [3,4] Furthermore, shoulder pain is a condition that progresses to chronic disease, making the subject's life difficult and uncomfortable for a long time. In addition, it causes functional impairment due to degenerative changes in the tissues and reduces patients' health-related quality of life [5]. Recently, shoulder pain has been found to be prevalent in people in their 30 s, and it is common in people of age $\geq 40$. Several diseases, such as adhesive capsulitis, rotator cuff tendinopathy, glenohumeral osteoarthritis, neurological and vascular diseases, etc., cause problems in the shoulder joint. In general, women have lower muscle strength and athletic ability than men, especially since the relaxation of muscles in women is affected by female hormones; this makes them more prone to musculoskeletal diseases, including shoulder pain, compared to men [6-8].

Shoulder pains and disorders have a negative impact on everyday life and also reduce the quality of life $[9,10]$. An individual's assessment of their overall satisfaction with respect to physical, mental, social, and psychological aspects of life is defined as quality of life [11]. The purpose of assessing health-related quality of life is to prevent disease and health, which is gaining increased attention in health-related research and practice [12]. In a previous study, it was reported that there is a significant correlation between women and shoulder pain, which is more frequent in women than men, but these shoulder pains 
and disorders have not been fully addressed [13-16]. Despite these previous studies, few studies have been conducted on the relationship between shoulder pains and disorders in middle-aged women in Korea. Therefore, it is necessary to understand the relationship between shoulder pain, shoulder disorder, and health-related quality of life in middle-aged women in Korea.

In a previous study, it was reported that chronic pain correlates with stress and living with chronic pain causes psychological stress [17]; therefore, people who have had negative experiences in life have a high risk of developing chronic musculoskeletal pain $[18,19]$. In particular, the degree of pain perceived is high in older people and people with high stress [20]. Therefore, it is necessary to identify whether the stress of middle-aged women in Korea directly affects shoulder pain and analyze how this relationship affects their health-related quality of life. According to previous studies, perceived stress is known to be a risk factor causing chronic shoulder pain $[21,22]$ and stress was found to be a factor that has negative effects on the quality of life [23]. In previous studies, the quality of life was lower in cases where physical functional limitations existed, [24] and depression was reported to be another factor that lowers the quality of life [25]. Furthermore, depression is more common in patients with musculoskeletal disease, especially when they have disabilities in performing activities of daily life [24]. Therefore, this study intends to investigate the relationship between stress and shoulder pain, shoulder pain and shoulder disorder, shoulder disorder and depression, and depression and health-related quality of life.

Based on previous studies, the purpose of this study is to identify the relationship between stress and health-related quality of life in middle-aged women and propose a serial multiple mediation model to understand this relationship. Based on the existing studies, we plan to investigate how stress directly and indirectly affects the health-related quality of life through mediators such as shoulder pain, shoulder disorder, and depression. When these predicted relationships are determined, we plan to validate the serial multiple mediation model to determine how much each variable affects one another.

\section{Methods}

\section{Study design and sample}

This is a survey study that examined the relationship between stress and the health-related quality of life in middle-aged women. Data was collected from 578 middle-aged women aged between 35 (inclusive) and 64 living in Seoul, Korea. The sample size of this study was analyzed using G*Power 3.1 analysis software. On performing power analysis under the conditions of medium effect size $=0.15$, power $=.95$, and significant level of $a=.05$, the minimum number of samples was calculated to be 199 . The total number of participants included in the study was 565 after considering the dropout rate. Therefore, the sample size of the current study is appropriate. The data was collected from May 13, 2021 to May 23, 2021. The selection criteria for the study were as follows: 1) women aged $\geq 35$ and 2) could communicate and complete a self-report survey.

\section{Measurement}




\section{Depression}

Patient Health Questionnaire (PHQ)-9, which is used to screen depression, is a self-reported questionnaire developed by Kroenke et al. [26] and adapted by Park et al. [27]. It consists of nine items that correspond to the diagnostic criteria of the major depression disorder based on the Diagnostic and Statistical Manual of Mental Disorders-IV. The Korean version of the PHQ-9 was adapted by Park et al. [27]. PHQ-9 is a test to evaluate how often these problems have been encountered in the last two weeks. The response of each tool is evaluated on a four-point scale as follows: 0 points for "never," 1 point for "a few days," 2 points for "more than one week," and 3 points for "almost every day." The score ranges from 0 to 27 points. In general, the study of Kroenke et al. [26] also suggested four break points of PHQ-9 that divide the level of depression into four groups according to severity (minimal, $0-4$; mild, 5-9; moderate, 10-14; moderate-to-severe, 15-19; and severe, 20 or more). Park et al. [27] suggested that a depressive disorder can be suspected when the total PHQ-9 score is $>5$ points. In the study by Park et al. [27], Cronbach's alpha was 0.81 , whereas it was 0.85 in this study, indicating a high reliability.

\section{Shoulder Pain and Disorder Index}

This tool was developed by Roach et al. [28] to evaluate the degree of pain and disorder of the shoulder and adapted by Seo et al. [29]. It consists of a total of 13 questions and is divided into two supplementary scales that include 5 questions in the subscale of pain to evaluate the degree of pain of the individual and 8 questions in the subscale of function/disorder designed to evaluate the degree of disorder of upper limb movement when performing different activities of daily living. A total of 13 items are evaluated on a 10-point scale, 0 point is scored if there is no pain and 10 points if the pain is very severe. The results of each tool were converted into a 100-point scale. The higher the score obtained from this tool, the greater the degree of shoulder pain or damage and disorder. Cronbach's alpha was 0.94 at the time of the development of the tool. Cronbach's alpha in this study is 0.94 , indicating high reliability

\section{Stress}

Stress is a measure of how much an individual perceives a specific condition as stressful. We used the Korean Perceived Stress Scale (PSS) adapted by Lee et al. [30] from PSS developed by Cohen et al. [31] to measure perceived stress. The tool consists of a total of ten questions, and all questions are assessed by a five-point Likert scale ranging from never (0 points) to very often (4 points). In the study of Lee Jong $\mathrm{Ha}$, the Cronbach's alpha of the tool was 0.88 , whereas it is 0.96 in this study, showing a high reliability. Total points range from 0 to 40 , where $0-13$ points indicate low-level stress, 14-26 points indicate normal-level stress, and 27-40 points indicate high-level stress.

\section{Health-related quality of life}

As a tool for evaluating the health-related quality of life, the Medical Outcome Study 12-item Short Form Health Survey (SF-12) developed by Ware et al. [32] was used. The tool is divided into eight subregions for the two main parts-Physical Component Summary (PCS-12) and Mental Component Summary (MCS-12). It consists of a total of 12 questions. The score of each subregion is converted to a range of 
0-100 points regardless of the number of questions and according to the specified calculation method of SF-12. The higher is the score, the higher is the quality of life. SF-12 is often used to assess the quality of life in relation to health, and its reliability and validity have been proven for all ages. [33]. Cronbach's a was 0.86 at the time of development of this tool, and in this study, it is 0.86 , which shows a high reliability.

\section{Ethical considerations}

This study is in accordance with the principles of the Helsinki Declaration, and the study plan and process were approved by the Clinical Ethics Committee of the University of Daejeon University. All participants signed a written consent before the start of the survey after a detailed explanation of the purpose and method of the study was provided to each participant in person. The participants were informed that the participation in the study is voluntary, they will not be at any disadvantage during the participation in the study, and that they can withdraw participation at any time if they wish. The survey was distributed only to participants who agreed to participate, and the collected data were used for study purposes only. The guarantee of anonymity and autonomy of study participants was described. The collected survey was stored in a secured cabinet.

\section{Statistical analyses}

All the study data were processed using SPSS for performing descriptive statistics and correlation analyses. To verify the mediating effect of shoulder pain, shoulder disorder, and depression in the relationship between stress and health-related quality of life, Hayes's PROCESS macro (Model 6) was used for analysis. In serial mediation, mediating factors (shoulder pain, shoulder disorder, and depression) are expected to affect the quality of life directly and indirectly. The serial mediation model is a useful study model to identify the precedence between three mediating variables in the relationship between stress and health-related quality of life. In this model, the first mediating variable (shoulder pain) sequentially affects the second mediating variable (shoulder disorder) and the second mediating affects the third mediating variable (depression). The bootstrapping process of SPSS PROCESS macro was used to test the mediating effects in this study [34]. By random sampling, 10,000 samples were generated, and $95 \%$ bias-corrected confidence interval $(\mathrm{BC} \mathrm{Cl})$ was employed for the analysis of the mediating effects [35]. If the $95 \% \mathrm{Cl}$ did not cover zero, the effect was considered significant.

\section{Results}

\section{Participants' general characteristics and differences}

The general characteristics of the participants are shown in Table 1. A total of 589 participants answered the survey, and 565 participants were included in the analysis excluding those with incomplete responses to the self-reported survey and who dropped out from the study (the response rate was $95.9 \%$ ). All middleaged women $(\mathrm{N}=565)$ were aged between 35 and 63 , and the average age of participants was 42.15 $( \pm 6.37)$. With respect to marital status, majority of the participants were married $(72.7 \%)$, and in terms of 
the level of education, those with a college degree or a higher level of education constituted $80.2 \%$ participants. With regard to regular exercise, $52.2 \%$ participants responded that they do not exercise regularly and $47.8 \%$ responded that they do. Furthermore, $96.8 \%$ participants were non-smoker, and $53.1 \%$ did not consume alcohol. Regarding financial condition, $83.2 \%$ participants responded that they are in the middle or higher class of income. The average working hours of the participants was $7.08(2.77) \mathrm{h}$ per day, and the average sitting hours during work were $4.06(2.90) \mathrm{h}$. It was found that $64.2 \%$. of participants had no chronic disease. Depression levels measured with PHQ-9 showed that minimal depression was the most common (39.6\%) followed by mild depression (35.4\%). 
Table 1

Descriptive statistics of study population $(N=565)$

\begin{tabular}{|c|c|c|}
\hline Variable & $\mathrm{N}(\%)$ & Mean (SD) \\
\hline Mean Age (years) (range) & & 42.15 (6.37) (35-63) \\
\hline \multicolumn{3}{|l|}{ Marital status } \\
\hline Single & $141(25.0)$ & \\
\hline Married & 411 (72.7) & \\
\hline Divorced \& Widowed & $13(2.3)$ & \\
\hline \multicolumn{3}{|l|}{ Education } \\
\hline$\geq$ Middle school & $112(19.8)$ & \\
\hline College & $453(80.2)$ & \\
\hline \multicolumn{3}{|l|}{ Exercise } \\
\hline Yes & $270(47.8)$ & \\
\hline No & $295(52.2)$ & \\
\hline \multicolumn{3}{|l|}{ Smoking } \\
\hline Yes & $18(3.2)$ & \\
\hline No & $547(96.8)$ & \\
\hline \multicolumn{3}{|l|}{ Alcohol } \\
\hline Yes & 265 (46.9) & \\
\hline No & $300(53.1)$ & \\
\hline \multicolumn{3}{|l|}{ Economic status } \\
\hline$\geq$ Middle & $470(83.2)$ & \\
\hline Low & $95(16.8)$ & \\
\hline Sitting hours during work & & $4.06(2.90)$ \\
\hline Working hours per day & & $7.08(2.77)$ \\
\hline \multicolumn{3}{|l|}{ Chronic condition } \\
\hline Without & 363 (64.2) & \\
\hline With & $202(35.8)$ & \\
\hline \multicolumn{3}{|l|}{ Depression } \\
\hline Minimal & 224 (39.6) & \\
\hline
\end{tabular}




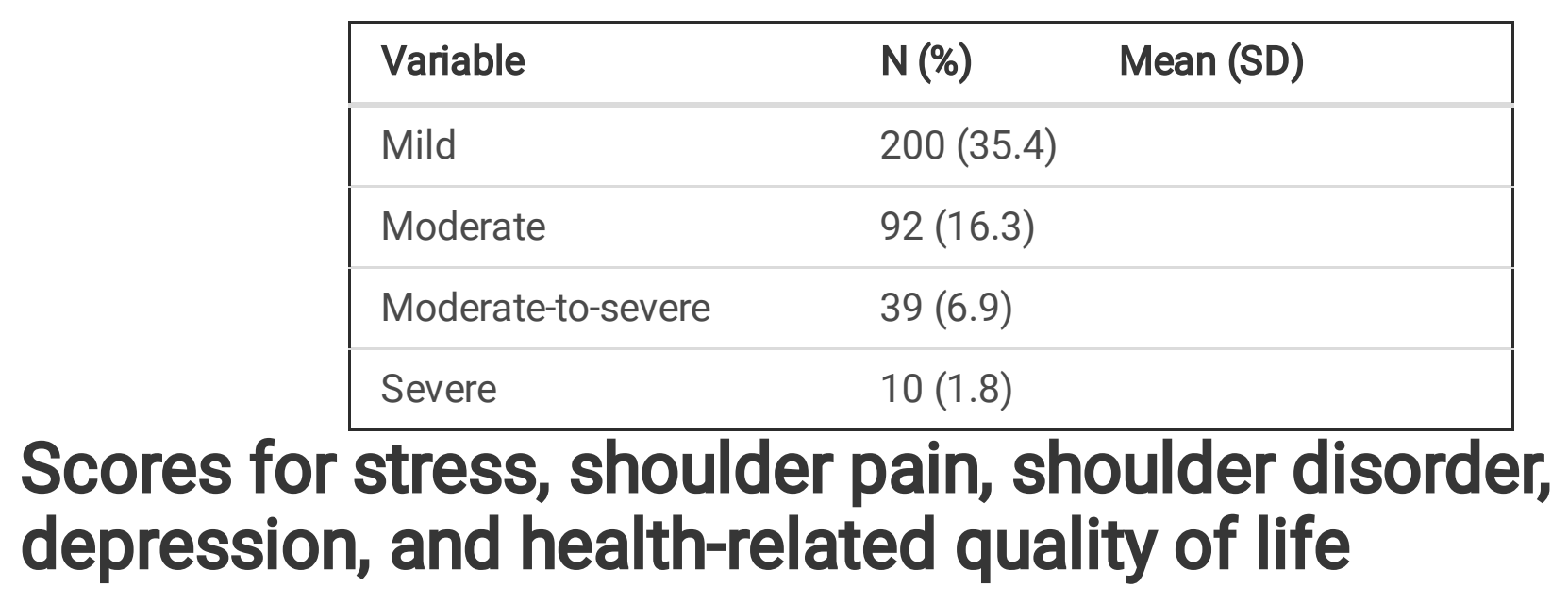

As shown in Table 2, the overall average score for health-related quality of life was 66.28 (10.00), the average score obtained using PCS-12 was 65.28 (10.09), and MCS-12 was 67.15 (11.88). The average score for depression was 6.73 (5.14) points, which is $\geq 5$ points according to overall average, suggesting depressive disorder. The average stress score was 18.99 (5.47) points, which is at a normal level. The average score for shoulder pain was 42.68 (25.06) points out of 100 , and the average score for shoulder disorder was 26.82 (23.54) points out of 100.

Table 2

Level of stress, shoulder pain, shoulder disorder, depression, and health-related quality of life $(N=$ 565)

\begin{tabular}{|lll|}
\hline Variables & Min-Max & Mean (SD) \\
\hline Health-related quality of life & $25-91.07$ & $66.28(10.00)$ \\
\hline PCS & $23.08-88.46$ & $65.28(10.09)$ \\
\hline MCS & $20-100$ & $67.15(11.88)$ \\
\hline Depression & $0-27$ & $6.73(5.14)$ \\
\hline Stress & $4-38$ & $18.99(5.47)$ \\
\hline Shoulder pain & $0-100$ & $42.68(25.06)$ \\
\hline Shoulder disability & $0-100$ & $26.82(23.54)$ \\
\hline Note. SD, Standard Deviation; PCS, Physical component score; Mcs, Mental component score. & Orrelations between stress, Shoulder pain, shoulder \\
Sorder, depression, and health-related quality of life
\end{tabular}

The results obtained after analyzing the correlation between variables are shown in Table 3. It was found that the health-related quality of life had a negative correlation with stress $(r=-0.001, p=0.984)$, depression $(r=-0.261, p<0.001)$, shoulder pain $(r=-0.103, p=0.015)$, and shoulder disorder $(r=-0.234$, $p<0.001)$. The higher was the stress, the worse was the depression; the severe the shoulder pain and shoulder disorder, the lower was the health-related quality of life. Stress was found to have positive 
correlations with depression ( $r=0.589, p<0.001)$, shoulder pain $(r=0.221, p<0.001)$, and shoulder disorder $(r=0.228, p=0.004)$. Furthermore, depression was found to have positive correlations with shoulder pain $(r=0.357, p<0.001)$ and shoulder disorder $(r=0.366, p<0.001)$. There was a positive correlation between shoulder pain and shoulder disorder $(r=0.694, p<0.001)$. In other words, the higher was the stress, the worse were the shoulder pain and shoulder disorder in addition to a higher depression level. Also, when the shoulder pain and shoulder disorder were severe, the depression level was also high, and the worse the shoulder pain, the higher the shoulder disorder.

Table 3

Correlations among study variables $(N=565)$

\begin{tabular}{|c|c|c|c|c|c|}
\hline & $\begin{array}{l}\text { Health-related } \\
\text { quality of life }\end{array}$ & Stress & Depression & $\begin{array}{l}\text { Shoulder } \\
\text { pain }\end{array}$ & $\begin{array}{l}\text { Shoulder } \\
\text { disability }\end{array}$ \\
\hline $\begin{array}{l}\text { Health-related } \\
\text { quality of life }\end{array}$ & - & & & & \\
\hline Stress & $-.249(<.001)$ & - & & & \\
\hline Depression & $-.261(<.001)$ & $\begin{array}{l}.589 \\
(<.001)\end{array}$ & - & & \\
\hline Shoulder pain & $-.103(.015)$ & $\begin{array}{l}.221 \\
(<.001)\end{array}$ & $\begin{array}{l}.357 \\
(<.001)\end{array}$ & - & \\
\hline Shoulder disability & $-.234(<.001)$ & $\begin{array}{l}.228 \\
(.004)\end{array}$ & $\begin{array}{l}.366 \\
(<.001)\end{array}$ & $\begin{array}{l}.694 \\
(<.001)\end{array}$ & - \\
\hline
\end{tabular}

\section{Mediating effects}

A serial multiple mediation model was developed using the Hayes's SPSS macro PROCESS (Model 6, Figure 1). Table 4 illustrates the findings of the tested model and how shoulder pain, shoulder disorder, and depression mediate the relationship between stress and health-related quality of life in middle-aged women. As it may be noticed, there is a significance in both the total effect $(B=-0.4408, S E=0.0773, t=$ $-5.7020, p<0.001)$ and the direct effect $(B=-0.2598, S E=0.0934, t=-2.7816, p=0.0056)$ of stress on quality of life. The impact of stress on health-related quality of life was reduced when shoulder pain, shoulder disorder, and depression were removed, but it became significant when they were added to the model as the mediators. The effect of serial multiple mediation model was found to be statistically significant in predicting health-related quality of life from shoulder pain, shoulder disorder, and depression, and the explanatory power of variables for quality of life was $33 \%$. $\left(R^{2}=0.33, F=16.671, p<\right.$ $0.001)$.

The bootstrapped indirect effect of stress on quality of life via shoulder pain, shoulder disorder, and depression was found to be significant $(\mathrm{B}=-0.1809, \mathrm{SE}=0.0652,95 \% \mathrm{BC} \mathrm{Cl}[-0.3140-0.0586])$; in other words, the indirect effects of stress through the mediators as well as the direct effects of stress were both found to be significant, indicating a partial mediatng effect of shoulder pain, shoulder disorder, and depression. 
Table 4

Total, direct, and indirect effects for multiple mediator model $(N=565)$

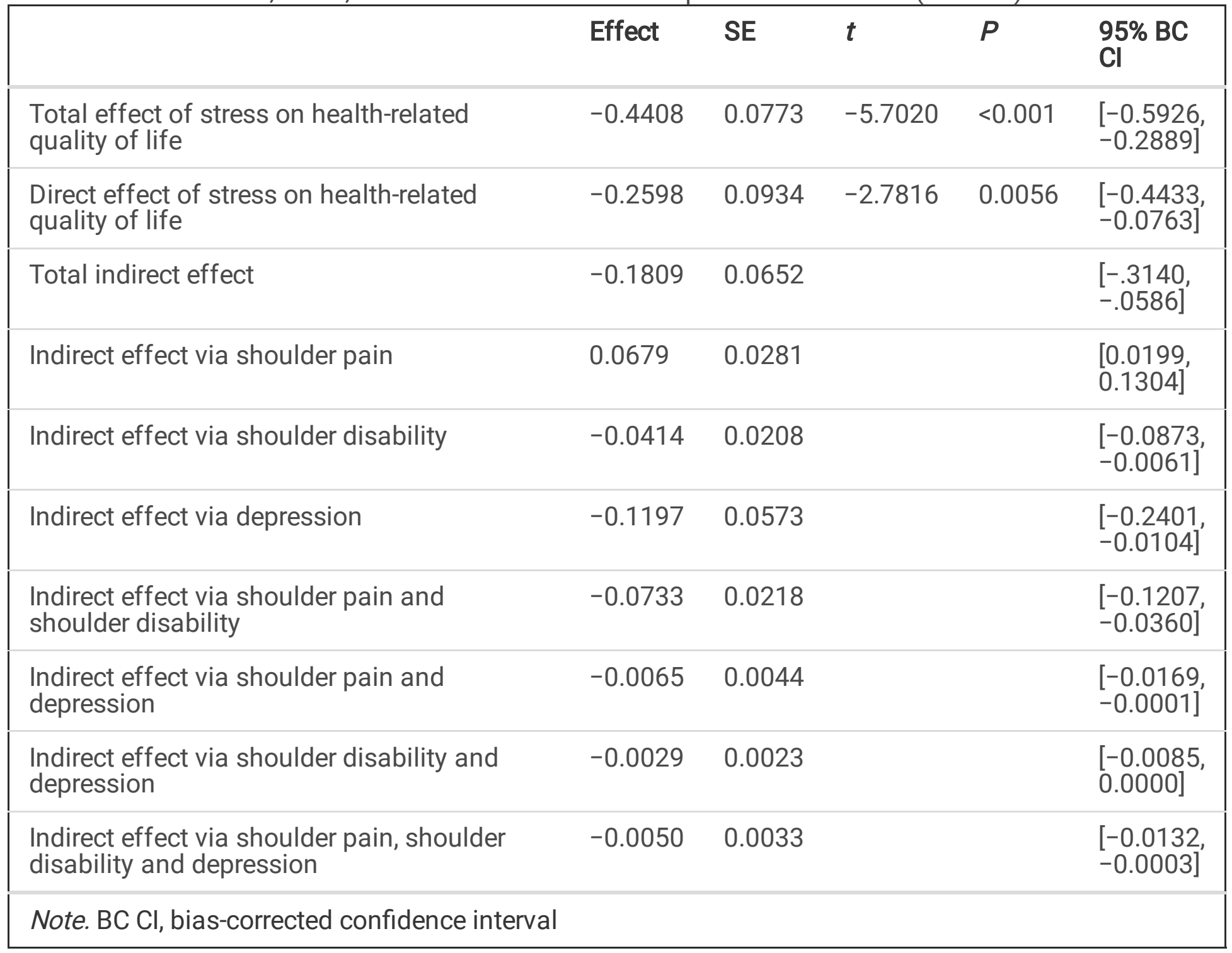

\section{Discussion}

The present study evaluated how the underlying mechanisms of shoulder pain, shoulder disorder, and depression mediates the relationship between stress and health-related quality of life in middle-aged women. As is consistent with our conceptual framework, it was determined that (1) stress was negatively correlated with health-related quality of life; (2) shoulder pain, shoulder disorder, and depression mediated the relationship between stress and health-related quality of life; and (3) these three mediators were involved in the indirect effects of stress on health-related quality of life in a sequential manner.

Similar to previous studies, our data also show a close relationship between stress and health-related quality of life. [36,37] Stress is a risk factor for poor physical and mental health [38]. Middle-aged women in Korea experience a higher number of unfortunate life events compared to men, which include a variety of factors such as pregnancy, giving birth, child care, separation, divorce, job loss, and diseases or death of family members. When compared to men, women have different social roles within the family. Their 
household duties are repetitive and unpaid despite the fixed duration of working hours. Therefore, compared to men, women are more vulnerable to stressors or stresses that threaten their social or daily life [39].

Social support at work and home is a factor that can positively affect an individual's physical and mental health and reduce stress [40,41]; therefore, to improve the health-related quality of life of middle-aged women, systematic family and social support that can reduce and control stress should be provided. In this study, stress has a direct as well as an indirect effect on the health-related quality of life through shoulder pain and shoulder disorder. Psychosocial factors such as stress or anxiety further activate pain perception [42,43]. Shoulder pain often recurs after recovery [44] and, sometimes, becomes a chronic condition (lasting for more than 3 months). It may occur alone or is accompanied by neck or upper back pain [45].

Humans perceive stress, have the ability to modify it, and know how to respond to it. Therefore, to reduce shoulder pain or shoulder disorder caused by stress, it is important to raise the ability to adjust to stress and the threshold of enduring it. Based on the fact that chronic pain could be controlled by proper exercise and the effects of exercise are well known in stress management [46], it is necessary to conduct an intervention study in the future to control stress and pain through an exercise that can be integrated into the lives of middle-aged women.

In this study, it was shown that stress has a direct as well as indirect effect on the health-related quality of life through shoulder pain, shoulder disorder, and depression. The results are consistent with previous studies $[47,43]$, showing that the higher the depression level, the lower the health-related quality of life and the higher the pain, the higher the depression level and the lower the health-related quality of life [48]. The results of this study suggest that stress directly affects the health-related quality of life and causes shoulder pain, shoulder disorder, and depression, and all of these mediating variables have a direct and indirect effect on the health-related quality of life. Therefore, it is proven that controlling and managing stress is an important factor in improving the health-related quality of life. Stress has a secondary effect on physical symptoms, such as pain and disorder, and mental symptoms, such as depression, as well as a negative effect on the quality of life.

Therefore, healthcare workers, such as nurses, need to implement nursing interventions that prevent and control stress caused by various complex factors that middle-aged women experience. In a previous study [46], it was reported that stress can be controlled through exercise and physical activity. It was also reported that exercise improves shoulder pain, shoulder disorder, depression, and health-related quality of life $[49,50]$. Therefore, in future studies, it is necessary to develop an intervention program that includes various degrees and types of physical activity for reducing the stress experienced by women in their daily lives, restoring the physical health of women with symptoms of physical conditions and disabilities, and managing mental health conditions such as depression, thereby helping and supporting them to live a healthy and happy life. 


\section{Limitations}

This study has several limitations. First, only participants living in Seoul, South Korea were sampled using convenience sampling. Therefore, the results of this study cannot be extrapolated to the middleaged women of other countries. Second, this study analyzed relationships and directions between stress, health-related quality of life, shoulder pain, shoulder disorder, and depression based on the self-report survey of the participants. Therefore, cause-and-effect interpretations on variables cannot be established. In a future study, the analysis and interpretation of data should be conducted using tools that can be used to perform a more detailed and objective evaluation of various factors that affect the health-related quality of life in middle-aged women. Despite the limitations of this study, it provides a new insight into the relationship between stress and health-related quality of life and analyzes the degree of direct and indirect effects of shoulder pain, shoulder disorder, and depression on stress. Furthermore, this study suggests that for improving the health-related quality of life of middle-aged women and reducing stress, it is necessary to develop interventions that can reduce and manage shoulder pain and shoulder disorder and reduce the depression caused by these physical symptoms.

\section{Conclusions}

This study aimed to analyze the relationship between stress and health-related quality of life using serial mediation analysis. The direct effect of stress on the health-related quality of life was found to be statistically significant. In addition, according to the serial mediation analysis, the indirect effect of stress on health-related quality of life through shoulder pain, shoulder disorder, and depression were also found to be statistically significant, and the explanatory power of these variables affecting the health-related quality of life was $33 \%$. The results of this study highlighted the importance of stress in maintaining the health-related quality of life and suggested the need for developing specific health promotion programs (e.g., exercise programs) to reduce and control stress. The results of this study suggest that it is essential for healthcare workers to develop and implement exercise intervention programs to reduce stress, shoulder pain, shoulder disorder, and depression in middle-aged women. It is certain that consistent efforts, such as the development of these exercise intervention programs and the evaluation of their effects, will enable middle-aged women to lead healthy lives and improve their health-related quality of life.

\section{Abbreviations}

PHQ, Patient Health Questionnaire: PCS, Physical Component Summary: MCS, Mental Component Summary: PSS, Perceived Stress Scale: SF-12, 12-item Short Form Health Survey

\section{Declarations}

\section{Ethics approval and consent to participate}


This study is in accordance with the principles of the Helsinki Declaration, and the study plan and process were approved by the Clinical Ethics Committee of the University of Daejeon University. All participants signed a written consent before the start of the survey after a detailed explanation of the purpose and method of the study was provided to each participant in person. The participants were informed that the participation in the study is voluntary, they will not be at any disadvantage during the participation in the study, and that they can withdraw participation at any time if they wish.

\section{Consent for publication}

Not Applicable.

\section{Availability of data and materials}

The data presented in this study are available on request from the corresponding author. The data are not publicly available due to privacy.

\section{Competing interests}

The authors declare that the research was conducted in the absence of any commercial or financial relationships that could be construed as a potential conflict of interest.

\section{Funding}

This research was funded by the National Research Foundation of Korea (NRF) grant of the Korea government (MSIT), grant number 2020R1C1C1015358.

\section{Authors' contributions}

Conceptualization, J.O.; methodology, M.L.; software, M.L.; validation, J.O.; formal analysis, J.O.; investigation, J.O.; resources, M.L.; data curation, M.L and J.O.; writing-original draft preparation, M.L. and J.O.; writing-review and editing, M.L. and J.O.; visualization, M.L. and J.O.; supervision, M.L.; project administration, J.O. All authors have read and agreed to the published version of the manuscript.

\section{Acknowledgments}

Not applicable 


\section{References}

1. Luime JJ, Koes BW, Hendriksen IJ, Burdorf A, Verhagen AP, Miedema HS, et al. Prevalence and incidence of shoulder pain in the general population; a systematic review. Scand J Rheumatol. 2004;33:73-81.

2. van der Windt DA, Koes BW, de Jong BA, Bouter LM. Shoulder disorders in general practice: incidence, patient characteristics, and management. Ann Rheum Dis. 1995;54:959-64.

3. van der Windt DA, Koes BW, Boeke AJ, Devillé W, De Jong BA, Bouter LM. Shoulder disorders in general practice: prognostic indicators of outcome. Br J Gen Pract. 1996;46:519-23.

4. Winters JC, Sobel JS, Groenier KH, Arendzen JH, Meyboom-de Jong B. The long-term course of shoulder complaints: a prospective study in general practice. Rheumatology (Oxford). 1999;38:160-3.

5. MacDermid JC, Ramos J, Drosdowech D, Faber K, Patterson S. The impact of rotator cuff pathology on isometric and isokinetic strength, function, and quality of life. J Shoulder Elbow Surg. 2004;13:593-8.

6. Baghi R, Rahnama L, Karimi N, Goodarzi F, Rezasoltani A, Jaberzadeh S. Differential activation of the dorsal neck muscles during a light arm-elevation task in patients with chronic nonspecific neck pain and asymptomatic controls: an ultrasonographic study. PM R. 2017;9:699-706.

7. Lindbeck L, Kjellberg K. Gender differences in lifting technique. Ergonomics. 2001;44:202-14.

8. Shultz SJ. The effect of sex hormones on ligament structure, joint stability and ACL injury risk. In: Hackney A, editor. Sex hormones, exercise and women. Cham: Springer; 2017. p. 113-38.

9. Gutierrez DD, Thompson L, Kemp B, Mulroy SJ. The relationship of shoulder pain intensity to quality of life, physical activity, and community participation in persons with paraplegia. J Spinal Cord Med. 2007;30:251-5.

10. Walankar PP, Panhale VP, Patil MM. Psychosocial factors, disability and quality of life in chronic shoulder pain patients with central sensitization. Health Psychol Res. 2020;8:8874.

11. Van Knippenberg FC, De Haes JC. Measuring the quality of life of cancer patients: psychometric properties of instruments. J Clin Epidemiol. 1988;41:1043-53.

12. Alzboon G, Vural G. Factors influencing the quality of life of healthy pregnant women in North Jordan. Medicina (Kaunas). 2019;55:278.

13. Dianat I, Bazazan A, Souraki Azad MA, Salimi SS. Work-related physical, psychosocial and individual factors associated with musculoskeletal symptoms among surgeons: implications for ergonomic interventions. Appl Ergon. 2018;67:115-24. 
14. Khosravi F, Amiri Z, Masouleh NA, Kashfi P, Panjizadeh F, Hajilo Z, et al. Shoulder pain prevalence and risk factors in middle-aged women: a cross-sectional study. J Bodyw Mov Ther. 2019;23:752-7.

15. Treaster DE, Burr D. Gender differences in prevalence of upper extremity musculoskeletal disorders. Ergonomics. 2004;47:495-526.

16. Kwon I, Oh J. Effects of 12 weeks of yoga program on muscle function and pain of shoulder in middle aged women with frozen shoulder. Korea J Sport. 2017;15:511-20.

17. Generaal E, Vogelzangs N, Macfarlane GJ, Geenen R, Smit JH, de Geus EJ, et al. Biological stress systems, adverse life events and the onset of chronic multisite musculoskeletal pain: a 6-year cohort study. Ann Rheum Dis. 2016;75:847-54.

18. Abdallah CG, Geha P. Chronic pain and chronic stress: two sides of the same coin? Chronic Stress (Thousand Oaks). 2017;1:2470547017704763.

19. Sheng J, Liu S, Wang Y, Cui R, Zhang X. The link between depression and chronic pain: neural mechanisms in the brain. Neural Plast. 2017;2017:9724371.

20. White RS, Jiang J, Hall CB, Katz MJ, Zimmerman ME, Sliwinski M, et al. Higher perceived stress scale scores are associated with higher pain intensity and pain interference levels in older adults. J Am Geriatr Soc. 2014;62:2350-6.

21. Bongers PM, Kremer AM, ter Laak J. Are psychosocial factors, risk factors for symptoms and signs of the shoulder, elbow, or hand/wrist?: a review of the epidemiological literature. Am J Ind Med. 2002;41:315-42.

22. Larsson B, Søgaard K, Rosendal L. Work related neck-shoulder pain: a review on magnitude, risk factors, biochemical characteristics, clinical picture and preventive interventions. Best Pract Res Clin Rheumatol. 2007;21:447-63.

23. Bae YH, Min KS. Associations between work-related musculoskeletal disorders, quality of life, and workplace stress in physical therapists. Ind Health. 2016;54:347-53.

24. Morken T, Riise T, Moen B, Bergum O, Vigeland Hauge SH, Holien S, et al. Frequent musculoskeletal symptoms and reduced health-related quality of life among industrial workers. Occup Med (Lond). 2002;52:91-8.

25. Oh J, Yi M. Structural equation modeling on quality of life in older adults with osteoarthritis. J Korean Acad Nurs. 2014;44:75-85.

26. Kroenke K, Spitzer RL, Williams JB. The PHQ-9: validity of a brief depression severity measure. J Gen Intern Med. 2001;16:606-13. 
27. Park SJ, Choi HR, Choi JH, Kim KW, Hong JP. Reliability and validity of the Korean version of the patient health questionnaire-9 (PHQ-9). Anxiety and Mood. 2010;6:119-24.

28. Roach KE, Budiman-Mak E, Songsiridej N, Lertratanakul Y. Development of a shoulder pain and disability index. Arthritis Rheumatol. 1991;4:143-9.

29. Seo H, Lee K, Jeong K, Chung Y. Reliability and validity of the Korean version of shoulder pain and disability index. J Spec Educ Rehabil Sci. 2012;51:319-36.

30. Lee J, Shin C, Ko YH, Lim J, Joe SH, Kim S, et al. The reliability and validity studies of the Korean version of the perceived stress scale. Korean J Psychosom Med. 2012;20:127-34.

31. Cohen S, Kamarck T, Mermelstein R. A global measure of perceived stress. J Health Soc Behav. 1983;24:385-96.

32. Ware J Jr, Kosinski M, Keller SD. A 12-Item Short-Form Health Survey: construction of scales and preliminary tests of reliability and validity. Med Care. 1996;34:220-33.

33. Gandek B, Ware JE, Aaronson NK, Apolone G, Bjorner JB, Brazier JE, et al. Cross-validation of item selection and scoring for the SF-12 Health Survey in nine countries: results from the IQOLA Project. International quality of life assessment. J Clin Epidemiol. 1998;51:1171-8.

34. Hayes AF. Introduction to mediation, moderation, and conditional process analysis: a regressionbased approach. New York: Guilford Publications; 2017.

35. Shrout PE, Bolger N. Mediation in experimental and nonexperimental studies: new procedures and recommendations. Psychol Methods. 2002;7:422-45.

36. Qi M, Li P, Moyle W, Weeks B, Jones C. Physical activity, health-related quality of life, and stress among the Chinese adult population during the COVID-19 pandemic. Int J Environ Res Public Health. 2020;17:6494.

37. Zhang H, Zhang Q, Gao T, Kong Y, Qin Z, Hu Y, et al. Relations between stress and quality of life among women in late pregnancy: the parallel mediating role of depressive symptoms and sleep quality. Psychiatry Investig. 2019;16:363-9.

38. Vines Al, Ta M, Esserman D, Baird DD. A comparison of the occurrence and perceived stress of major life events in black and white women. Women Health. 2009;49:368-80.

39. Williams D, Lawler KA. Stress and illness in low-income women: the roles of hardiness, John Henryism, and race. Women Health. 2001;32:61-75.

40. Blanco-Donoso LM, Garrosa E, Moreno-Jiménez B, de Almeida EC, Villela-Bueno SM. Social job resources as sources of meaningfulness and its effects on nurses' vigor and emotional exhaustion: a 
cross-sectional study among Spanish nurses. Curr Psychol. 2017;36:755-63.

41. Luo Y, Sato Y. Relationships of social support, stress, and health among immigrant Chinese women in Japan: a cross-sectional study using structural equation modeling. Healthcare (Basel). 2021;9:258.

42. Ortego G, Villafañe JH, Doménech-García V, Berjano P, Bertozzi L, Herrero P. Is there a relationship between psychological stress or anxiety and chronic nonspecific neck-arm pain in adults? A systematic review and meta-analysis. J Psychosom Res. 2016;90:70-81.

43. Turk DC, Wilson HD. Fear of pain as a prognostic factor in chronic pain: conceptual models, assessment, and treatment implications. Curr Pain Headache Rep. 2010;14:88-95.

44. Engebretsen KB, Grotle M, Natvig B. Patterns of shoulder pain during a 14-year follow-up: results from a longitudinal population study in Norway. Shoulder Elbow. 2015;7:49-59.

45. Grooten WJA; MUSIC Norrtälje Study Group. Predictors for persistent neck/shoulder pain, medical care-seeking due to neck/shoulder pain and sickness absence. Clin Rehabil. 2007;21:648-59.

46. Stults-Kolehmainen MA, Sinha R. The effects of stress on physical activity and exercise. Sports Med. 2014;44:81-121.

47. Han K, Yang S, Jia W, Wang S, Song Y, Cao W, et al. Health-related quality of life and its correlation with depression among Chinese centenarians. Front Public Health. 2020;8:580757.

48. Cherif F, Zouari HG, Cherif W, Hadded M, Cheour M, Damak R. Depression prevalence in neuropathic pain and its impact on the quality of life. Pain Res Manag. 2020;2020:7408508.

49. Koo K, Kim, K. Effects of different types of physical activity on health-related quality-of-life in Korean women with depressive disorder. Int J Environ Res Public Health. 2021;18:4639.

50. Tunwattanapong P, Kongkasuwan R, Kuptniratsaikul VJ. The effectiveness of a neck and shoulder stretching exercise program among office workers with neck pain: a randomized controlled trial. Clin Rehabil. 2016;30:64-72.

\section{Figures}




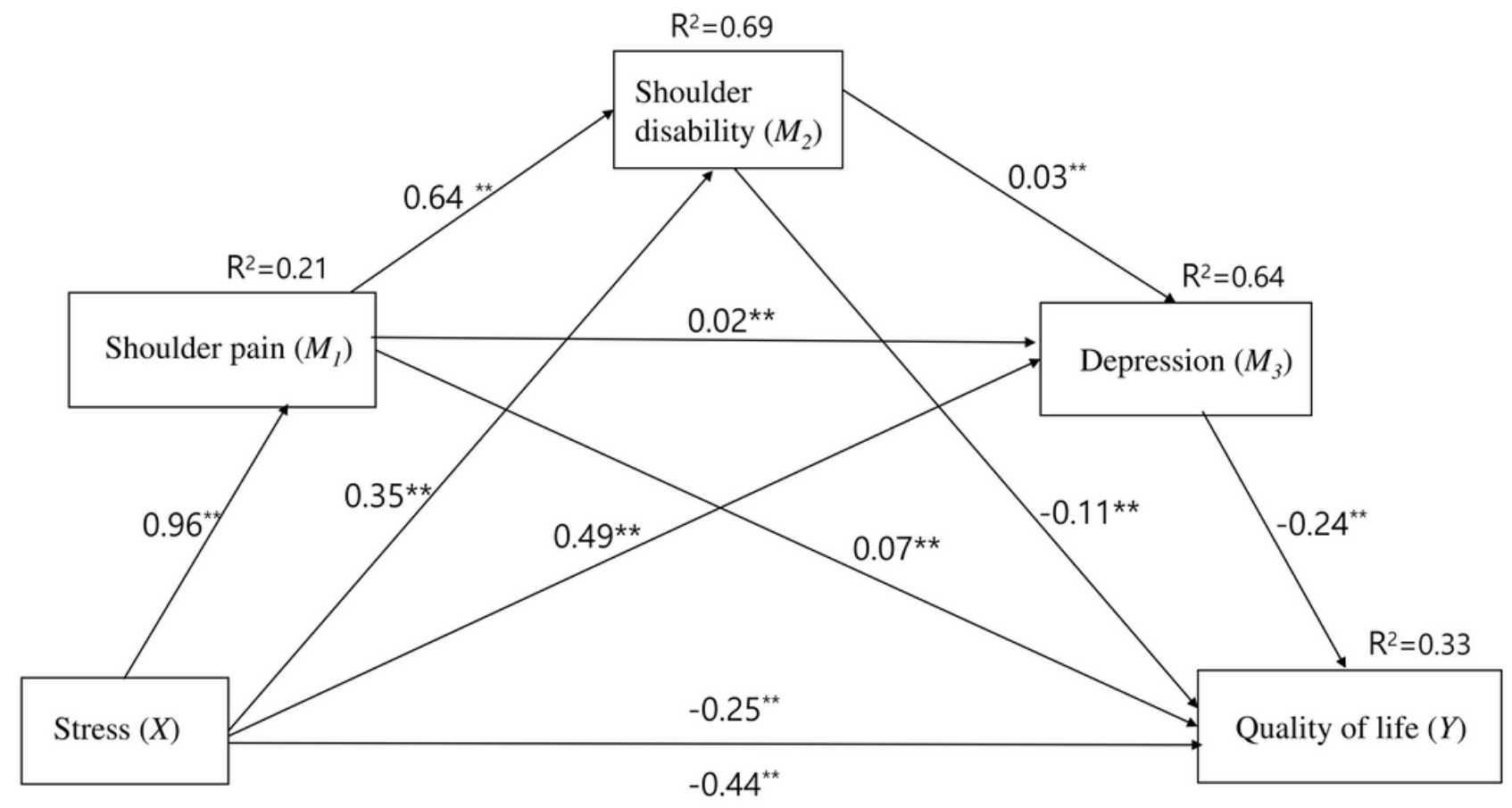

\section{Figure 1}

The results of the multiple mediation model testing social media use for shoulder pain, shoulder disability, and depression as mediators of the effect of stress on health-related quality of life. ${ }^{\star *} p<0.01$. 